\title{
Psychophysiological Studies of Unattended Information Processing
}

\author{
Fernando Valle-Inclán, Carmen de Labra, and Milagros Redondo \\ University of La Coruña
}

The article describes the general methods and some of the results obtained in the Psychophysiology Laboratory of the University of La Coruña. The paper covers our research on the Simon effect and accessory effect, although it is not a review of the literature. The research strategy we followed is built around the use of lateralized motor potentials recorded from scalp. These measures allow observing the way responses are selected and when they are selected, providing an invaluable tool to study response interference and to split reaction time into two halves. The research on the Simon effect concludes that interference during response selection is critical in the Simon effect but it is dubious whether this process should be considered as automatic and stimulus-driven, as is widely accepted. The experiments with the accessory effect indicate that facilitation is produced before response selection is over, which ends a long controversy about the locus of the accessory effect.

Keywords: Simon effect, accessory effect, ERP, LRP

El artículo describe el método y algunos de los resultados obtenidos en el laboratorio de Psicofisiologia de la Universidad de La Coruña. El trabajo abarca nuestra investigación sobre el efecto Simon y sobre el efecto accesorio, aurque no es una revisión del corpus teórico. La estrategia de investigación seguida en estos experimentos se basa en la utilización de potenciales motores lateralizados que se registran sobre cuero cabelludo. Estas medidas permiten observar cómo y cuándo se seleccionan las respuestas, proporcionando una valiosísima herramienta para estudiar la interferencia de respuesta y para partir el tiempo de reacción en dos mitades. Nuestra investigación sobre el efecto Simon concluye que la interferencia durante la selección de respuesta es crucial en el efecto Simon, pero no está tan claro si este proceso debe considerarse autornático y guiado por el estimulo, como detienden la mayoria de las teorías actuales. Los experimentos con el efecto accesorio indican que la facilitación se produce antes de que termine la selección de respuesta, lo que acaba con una larga controversia acerca del locus del efecto accesorio.

Palabras clave; efecto Simon, efecto accesorio, ERP, LRP

Acknowledgments: The research summatized in this paper was financed by the Spanish Ministry of Education and Science (PB961077) and Xunta de Galicia (XUGA-10406A94). We thank the Spanish Journal of Psychology for the invitation to write this article.

Correspondence to any of the authors concerning this article should be addressed to the Departamento de Psicología. Campus de Elviña. 15071 La Conña (Spain).E-mail addresses: fval@udc.es, clabra@mail2.udc.es, mredon@udc.es 
In this article, we discuss the aims, methods, and results of the Psychophysiology Laboratory at the University of La Coruña. The common thread of our work has been to study the way in which the processing of relevant information is affected by irrelevant information. We have investigated tasks in which a conflict between relevant and irrelevant information is produced, and others in which no such conflict occurs. The classic example of conflict phenomena is the Stroop Effect (Stroop, 1935), but there are others, such as the noise compatibility effect (Eriksen \& Eriksen, 1974) and the Simon effect (Simon \& Rudell, 1967). This latter phenomenon has been the focus of our work. For each of the three effects mentioned above, the typical outcome is faster reaction time (RT), and higher percentage of correct answers when the relevant and irrelevant information signals the same response, as opposed to different responses.

These conflict phenomena tend to be explained using a theoretical model developed by Kornblum, Hasbroucq, and Osman (1990) that, in essence, states one processing roule guided by the experimental instructions and another automatic route activated by the irrelevant information. These paths converge in the process of selecting responses, in such a way that interference is produced when two different responses are activated, and facilitation when only one is activated. Our investigation was initially centered on testing predictions from this model with measures derived from electroencephalogram (EEG) recordings. The general method is summarized in Section 1. The results confirmed that the Simon effect is produced by interference during response selection (that Gratton, Coles, and Donchin also demonstrated in 1992 for the noise compatibility effect). However, we have not been able to verify that the irrelevant information automatically activates a response. The data suggests, instead, that the influence of the irrelevant information depends on top-down processes. These studies may be found in Section 2.

We have also examined the role of irrelevant information when it is not associated with a response (unlike in the three examples cited above). Here, we focused on the accessory effect, which, basically consists of an RT that is faster when the imperative stimuli (generally visual) are accompanied by other stimuli (accessory stimuli, generally auditory), than when they are presented alone (see the review by Nickerson, 1973). Our results showed that effect was produced before response selection ended, and not further along in the processing sequence, as Sanders (1980) maintained (sce Section 3).

\section{Measurements Derived from EEGs: ERPs}

The electromagnetic fields produced by postsynaptic activity of synchronously activated neurons organized in an "open field" (i.e., aligned along a symmetry axis) generate an elcctromagnetic field that can be recorded at scalp as electrical activity (EEG) or as magnetic fields (magnetoencephalogram, MEG). The brain's response to stimulation involves neural activity related to the analysis of the stimulus ("signal") and that of the other neurons whose activity is not time-locked to the stimulation ("noise"). The magnitude of noise is several times larger than that of the signal, and thus, the first problem is separating signal from noise. The most common procedure is based on the fact that noise is a random variable whereas the signal is assumed to be constant. If those two assumptions hold, a coherent averaging (time point by time point) will abolish the noise (random values will tend toward the mean) and the signal will be visible. Recording from an array of electrodes, and interpolating values, yields a distribution of electrical potential over the scalp at each time point. This electrical distribution is produced by neural processing related to the event of interest (event-related potential, ERP). Obviously, one could also attain ERP time-locked to response (e.g., Hackley \& Valle-Inclálı, 1998).

The basic problem with the EEG and derived measures is that, generally speaking, it is not possible to locate the neurons responsible for the distribution of potential observed. The number of spatial configurations that could account for a particular distribution is endless, something that is referred to as the "insolubility of the inverse problem.." It could be argued that localization of the active structures is not one of the challenges of psychological investigation and that there are many questions that could be addressed without recourse to anatomy. The pioneer studies of Hillyard, Hink. Schwent, and Picton (1973) concerning auditory attention demonstrated that even without knowing the origin of recorded potentials, we can know when attended stimuli are differentiated from the unattended, and this information, in turn, is pertinent to the early/late selection debate.

Nonetheless, if one intends to go beyond a functional model (that is, a psychological model), one cannot dismiss the structural information. There are various ways to assign anatomical information to the ERPs, one of the most popular being the analysis of dipoles in combination with magnetic resonance imaging (MRI). However, we have to state that these are ad hoc methods that, at best, demonstrate only that the proposed dipole structure is compatible with the distribution of potential found. Nor can the combination of ERP and

1 The inverse problem is insoluble even when the recordings are of magnetic fields (MEG, magnetoencephalography), that are not distorted by the skull or scalp. If certain restrictions based on hypotheses, such as anatomical information, are imposed, then one could arrive at a solution to the inverse probjem, but this solution, though feasible, will nol be unique. 
functional magnetic resonance (FMRI) be considered a solution. In general, it is inexact to search for cenkers of activity with FMRI, and then place dipoles in the corresponding coordinates, and then generate at distribution of potential and compare it with the one obtained through ERP recording. It is inexact, despite the relation between blood flow and postsynaptic activity, because one cannot usually ascertain whether the activity reflected in FMRI corresponds to a closed ficld, in which case, it would not be reflected in the EEG. turthermort. even if one knows that the "lit up" area in l-MRI has neurons organized in an open field, the difference in temporal scale between ERP' and HMRI is so great (even in single-tral FMRI) that, at most, a coincidence between an FMRI locus and an equivalent dipole could be taken as suggestive.

Another solution to the spatial indetermination of ERPs is to work with those whose neural origins are known, thanks to invasive recording and experimentation with animals. These days, neural generators are known for potentials produced along the sensory pathways, before the activation reaches cortex. The utility of these very short latency potentials in the sudy of "superior" functions is certainly very limited. At cortical levels, we possess only a reasonable certainty regarding the origins of motor potentials that antecede movement and of early ( $<100 \mathrm{~ms}$ ) visual, auditory, and somatosensory contical potentials. Most of our reseatch was directly concerned with motor-related potentials preceding the execution of simple responses (such as pressing a key). It is generally agreed that these scalp-recorded potentials originate in the primary motor cortex. We have also utilized early visual potentials, which display retinotopic organization. Given the organization of Vl around the calcarine fissure, the polarity of the primary components is inverse for stimuli presented in the upper hemifield and in the lower hemifield (sec Valle-Inclán, Hackley, de Labra, \& Álvarez, 1999a, 1999b).

In the following section we present the method employed for obtaining potentials related to movement.

\section{Lateralized Readiness Potential (LRP)}

The LRP is an EEG-derived measurement that was developed simultancously and independently at the University of Groningen (de Jong, Wierda, Mulder, \& Mulder, 1988; Smid, Mulder, \& Mulder, 1987) and at the University of Illinois (Coles, 1989; Coles \& Gratton, 1986). The LRP is relatively easy to compute and nowadays, cheap to implement. but the information obtained is inversely proportionate to the procedure's simplicity, as will be detailed below.

Method for obtaining the LRP. Some hundredths of milliseconds before a hand or finger movement is executcd, a negative potential develops over the motor cortex (at positions $\mathrm{C} 3$ and $\mathrm{C} 4$ of the 10-20 international system, or at positions $1 \mathrm{~cm}$ anterior). This negative and symmetrical potential is known as the "readiness potential." Before execution of the movement, the readiness potential becomes more negative in the contralateral hemisphere of the hand that is to execute the response. By subtracting the potentials recorded over left and right hemispheres, the time point at which the readiness potential begins to lateralize will be observed. If the RT for left-and right-hand responses is similar, we can construct an aclivation index for the correct response by stbtracting loft- and right-hand responses. The result of this double subtraction (hemispheres, response hand) is known as the LRP (other names such as "corrected motor asymmetry," de Jong et al., 1988, ate no longer used).

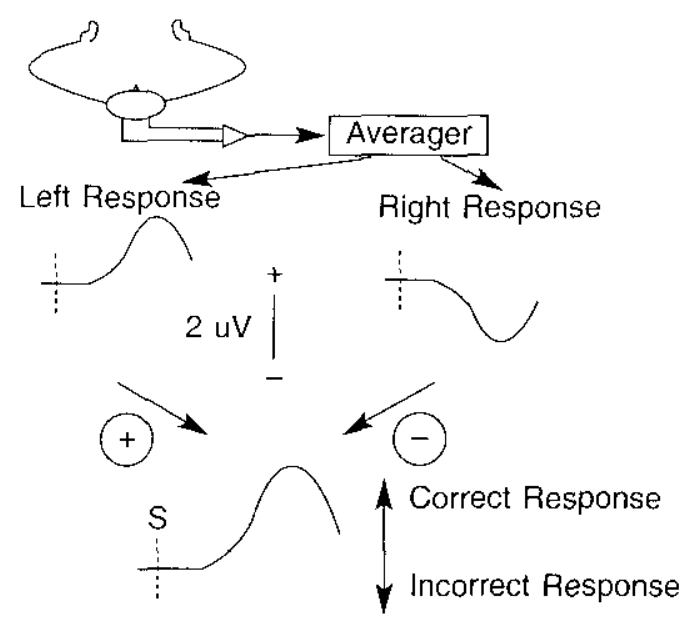

Figure 1 . LRP calculation.

There are several methods to compute the LRP (see Coles, 1989; Osman, Bashore, Coles, Donchin, \& Meher, 1992) but perhaps the easiest, in computational terms, is that of Osman et al. (1992):

$$
\mathrm{LRP}=(\mathrm{C} 3-\mathrm{C} 4)_{\mathrm{Left}}-(\mathrm{C} 3-\mathrm{C} 4)_{\mathrm{Right}}
$$

To further clarify the method, imagine the simplest experimental task: Stimuli presented centrally that require icftor right-hand responses. In this case, the L.RP can be obtained using on [y one EEG channe], a digital-to-analog converter, and a simple averaging program (see Figure 1). Connecting electrodes placed at the $\mathrm{C} 3$ and $C 4$ positions of the intemational system 10-20 (a C3-C4 "bipolar derivation") will yield the difference between left and right motor cortices (the first subtraction is done on-line). With this procedure, blinking and vertical ocular movements a common problem in EEG research) are nullified becausc the values are the same for both electrodes. Since the stimuli are presented centrally, there are no horizontal ocular movements (at least, not relevant to the task and, thereby, affecling the results) that could distort the EEG recording. EEG epochs will then be obtained and averaged according to the response hand and the stimulus type. Trials with keft-hand reactions will show a positive deflection whercas a negative wave will be observed on trials 
with right-hand reactions. Finally, ERPs for left- and righthand responses will be subtracted. More complex designs might also requirc eye-movement correction programs (Gratton, Coles, \& Donchin, 1983) or rejection of trials contaminated with ocular activity, or a larger array of electrodes.

Funcrional significance of the LRP. Figure 2 displays a minimalist model of information-processing stages for a choiceRT task. The figure includes three processing stages and the two psychophysiological markers (P300 and LRP) that were used to divide the interval between stimulus presentation and response execution. P300 latency had been considered for many ycars an adequate indicator of the end of the stimulus evaluation phase (c.g., McCarthy \& Donchin, 1981), despite the fact that many sludies indicated that factors implicated in response selection affected the latency of P300 (e.g., ValleInclán, 1996b). Verleger (1997) reviewed the literature on P300 latency and concluded that it is incorrect to consider P300 latency as a pure index of stimulus evaluation time.

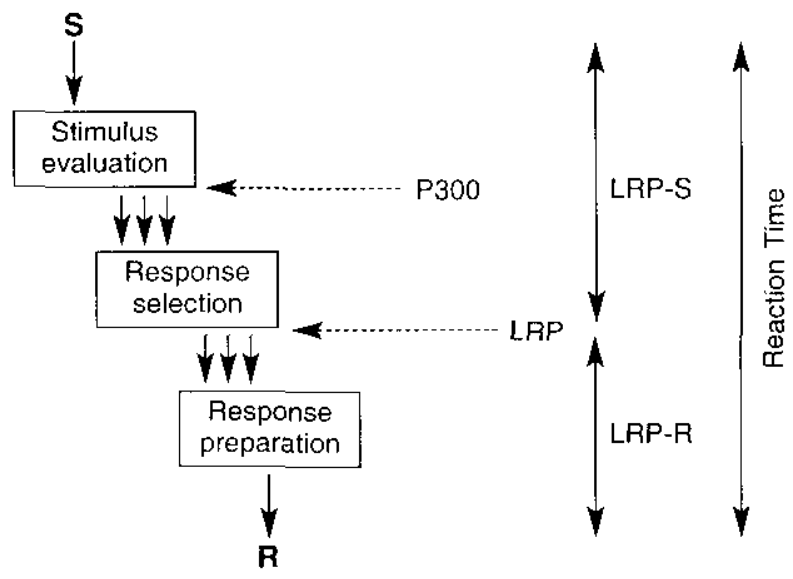

Figure 2. Minimalist model of information processing stages for choice-RT tasks.

However, the other psychophysiological index included in Figure 2, the LRP, is a measurement with clear functional significance and known neural origins. The LRP provides a method for dividing the RT in half and testing to see whether the observed behavioral effects are produced before or after response selection; additionally, it affords information about which responses were activated. Initiation of the LRP indicates the moment when one of the hands has been chosen to respond, that is, the end of the response selection stage. Therefore, the onset latency of the stimulus-locked LRP (LRP-S in Figure 2) indicates the time that elapses from stimulus presentation to the conclusion of response selection. Meanwhile, if we calculate the response-locked LRP (LRP-R in Figure 2), its onset latency indicates the time that elapses from response selection to its execution. In other words, the LRP onset allows us to halve the RT without having to assume a particular information-processing arquitecture or the way information is transmitted from one stage to the next. These two issues weigh heavily on a good many of the conclusions reached using behavioral measures. Our work with the accessory effect (see Section 3 ) is an example of the way one can utilize LRP to divide RT' and to determine the stage of information processing at which the observed effects in behavior are produced.

On the other hand, the form of the LRP enables us to know which responses were activated before response execution. Calculating the LRP according to the formula offered above, correct responses exhibit a positive LRP and incorrect responses a negative LRP. In this case, if only one response is activaled, the LRP will be positive, whereas if two responses are activated and the correct one is executed in the end (that is, if there is interference in the responseselection stage), the LRP will be biphasic: first a negative deflection, followed by a positive deflection. Our studies with the Simon effect (see Section 2) illustrate how LRP can be used to determine which responses are selected.

\section{The Simon Effect}

The Simon effect, first described by Simon and Rudell (1967) and so designated by Hedge and Marsh (1975). emerges in choice-RT tasks in which stimuli have a taskrelevant (c.g., color) and a task-irrelevant dimension (spatial location), and response keys are located in a manner congruent with the irtelevant stimulus spatial dimension. For example, the stimuli (two color patches) arc randomly presented at the left and right of the fixation point, and subjects answer by pressing keys that are also positioned at left and right. Under these conditions, the RT is faster in those trials in which the stimulus and response are ipsilateral (compatible trials) than in those in which the stimulus and

\section{Compatible}

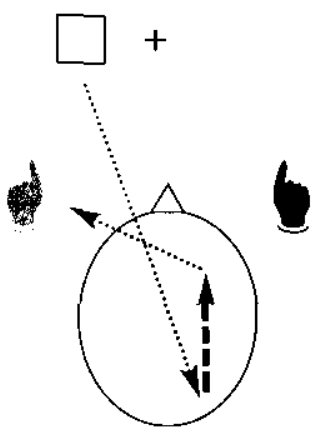

Incompatible

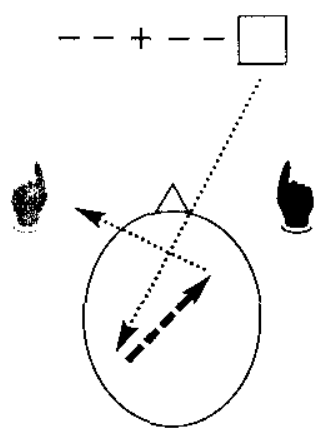

Figure 3. Anatomical hypothesis to explain the Simon effect. 
response are contralateral (incompatible trials). The effect is very consistent, it can be found in various sensory modalities, and it does not dissipate with practice (see the revisions of Lu \& Proctor, 1995; Simon, 1990).

Onc of the cxplanations for the Simon effect that first comes to mind is shown in Figure 3 . When the stimulus location and the required response are ipsilateral, stimulus and motor processing occur in the same hemisphere, whereas if stimulus and response are contralateral, an interhemispheric transmission is required. This explanation is false for many reasons, but the simplest and most convincing are the following: (a) If the hands are crossed over the midline in such a way that the right hand presses the left key and vice versa, the Simon effect is maintained (Simon, Hinrichs, \& Craft, 1970); and (b) if the two response keys are operated by two fingers of the same hand, the Simon effect also occurs.

In general, current explanations for the Simon effect hold the following: (a) The two attributes of the stimulus are processed in parallel, (b) spatjal localization processing automatically activates the spatially compatible response, and (c) this automatic activation of the compatible response is transitory and declines over time (Hommel, 1993a, 1994; Kornblum, et al., 1990; Kornb]um, Stevens, Requjn, \& Whipple, 1999). In our laboratory, we have striven to determine where the interference of inelevant information is generated and to what extent behavioral elfects can be considered the product of an automatic, stimulus-driven process.

\section{The Locus of the Simon Effect as Studied with LRP}

First, we attempted to elucidate at which processing stage (see Figure 2) the Simon effect is produced. At that

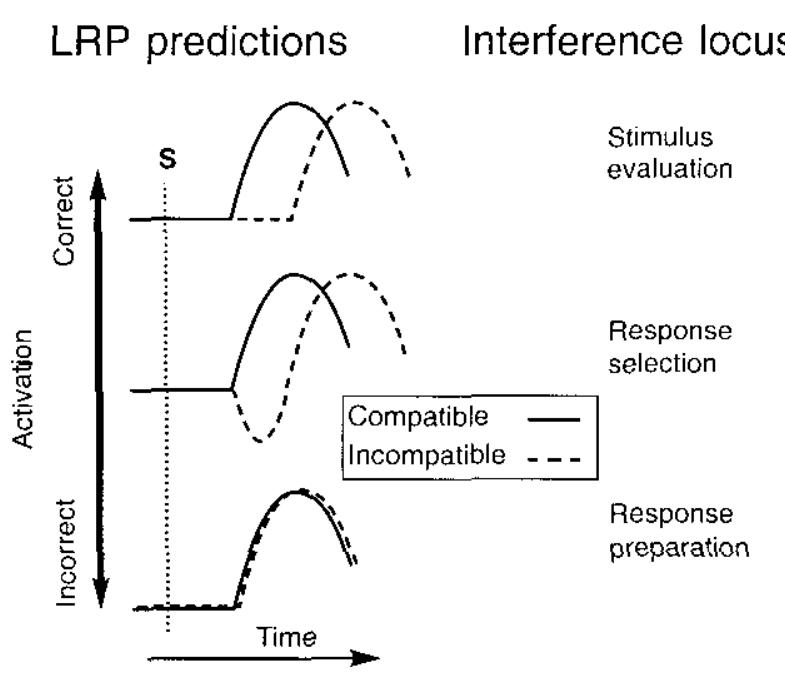

Figure 4. Stimulus-locked LRP predictions for diflerent interterence loci in the Simon effect. time, this was the subject of lively debate following the publication by Hasbroucq and Guiard (1991) of two experiments that seemed to demonstrate interference during stimulus evaluation. (Credit for the demonstration of the artifact that produced these results belongs to Hommel, 1995.)

A functional description of the Simon effect could begin with a model that is very similar to that of Figure 2. The model is quite generic, but it is an approximation that has proven to be useful for understanding and studying information processing in choice-RT tasks. Adopting this model as a basis, there are three possible loci for interference in the Simon effect, and each of them corresponds to a pattern of results of stimulus-locked LRP, as is represented in Figure 4.

It could be assumed that the conflict between the two dimensions is caused during perceptive processing (as claimed by Hasbroucq and Guiard, 1991) so that the system takes longer to classify a stimulus in incompatible than in compatible trials. If this were the casc, compatible trials would show earlier LRP onset than incompatible trials, without there being signs of incorrect response activation (see Figure 4, upper row). If, on the other hand, the Simon effect occurs during the response selection, the LRP should start at the same moment for both compatible and incompatible trials, but, for the latter, there would have to be ILRP signs of incorrect response activation (Figure 4 , center row). Lastly, if the Simon effect is produced during response preparation or execution, the stimulus-locked LRP should be the same for compatible and incompatible trials (Figure 4, lower row) and the differences would arise in the response-locked LRP (nol represented).
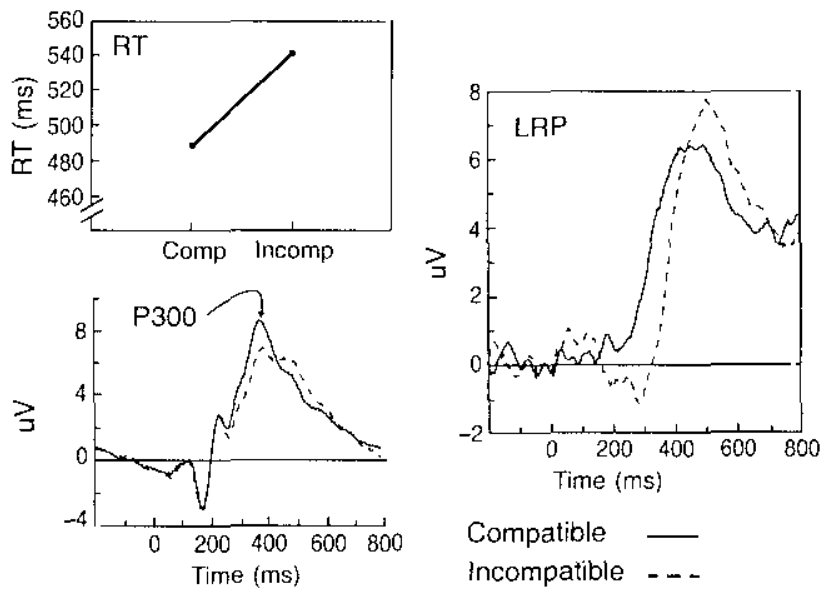

Figure 5. Typical RT and ERP results for a Simon task. The ERPs iltustrating the P300 effect were recorded at Pz. The LRP was obtained from recordings at $\mathrm{C} 3$ and $\mathrm{C} 4$. Data from Valle-Inclán (1996a, Experiment 3). 
With these hypotheses in mind, we conducted several experiments (Valle-Inclán, 1996a, 1996b) that consistently showed that LRP onset occurs at the same time for both compatible and incompatible trials and that, for the latter, the incorrect response is also activated. Figure 5 shows the results of one of these experiments (Valle-Inclán, 1996a, Experiment 3 ). In the upper left are the RT averages showing faster RT for compatible trials, In the lower left are the ERPs recorded in $\mathrm{Pz}$ for compatible and incompatible trials. Note that P300 is delayed for incompatible trials, as compared to computible trials. The LRP results are plotted on the right of Figure 5. LRP onsets are very similar for compatible and incompatible trials and that the incorrect response is activated (the negative dip in the graph) in the incompatible trials. This pattern of results is very clear and consistent, such that we can confidently state that response interference is a critical factor in the production of the Simon effect.

\section{The Automatic Character of the Simon Effect}

The usuai hypothesis argued to explain the Simon effect is that the abrupt stimulus onset automatically activates the compatible response (e.g., Craft \& Simon, 1970; de Jong, Liang, \& Lauber, 1994; Kornblum et al., 1990). There are various lines of conflicting evidence concerning this hypothesis. First of all, as it was originally presented, the hypothesis has trouble explaining the appearance of Simon effects when target and noise are simultaneously presented (e.g.,Valle-Inclán, 1996a, Experiment 2). Since, in these experiments (see also Grice, Canham, \& Burtoughs, 1984), the stimuli occupy both sides, it is obvious that the appearance of the stimulus cannot be responsible for the Simon effect. Recently, Shiu and Kornblum (1999) have proposed that the automatic activation of the compatible response can take place after identification of the stimulus, which could explain occurrence of the Simon effect in visual-search tasks.

Second, if the mere presentation of the stimulus, or its identification, activates the compatible response, one could cxpect that, with respect to neutral trials $(\mathrm{N})$, where no lateralized presentation exists, compatible trials (C) will exhibit facilitation $(\mathrm{C}<\mathrm{N})$, whereas incompatible trials (l) will exhibit interference $(\mathrm{N}<\mathrm{I})$. However, the comparison of compatible, neutral, and incompatible trials yields different results depending on the experimental design. For example, Simon and Small (1969) presented compatible and incompatible trials mixed in the same block, and neutrai trials in another block. Their results display a $\mathrm{N}<\mathrm{C}<\mathrm{I}$ pattern. Simon and Craft (1970) presented the three types of trials in the same block and achieved the aforementioned pattern, $\mathrm{C}<\mathrm{N}<\mathrm{I}$ (see also Hommel, 1993b; Umiltà, Rubichi, \& Nicoletti, 1999). Simon and Acosta (1982) showed that the presence of facilitation depends on the method of blocking used.

Third, the notion of an automatic activation of the compatible response cannot explain the inversion of the
Simon effect, which Hedge and Marsh (1975) were the first to describe. These authors utilized colored keys and presented colored patches. The task was to press the key of the same color as the stimulus (direct mapping condition) or of the opposite color (alternate mapping condition). In four different experiments, the stimuli were presented in a vertical or horizontal meridian and the responses arranged in a vertical or horizontal dimcnsion. The Simon effect showed up when stimuli and responses shared the same spatial dimension (vertical or horizontal), but only under direct mapping conditions. Surprisingly, the Simon effect was inverted under the alternate mapping condition. Since the work of Hedge and Marsh, two other ways to invert the Simon effect have been reported (Hommel, 1993b; Proctor \& Lu, 1999).

\section{LRP results}
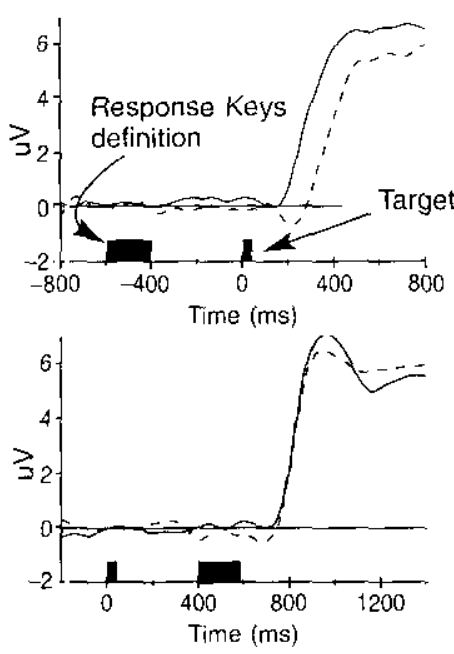

\section{LRP predictions}
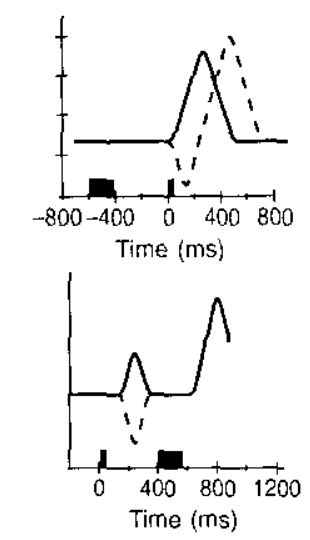

Compatible -

Incompatible =- -
Figure 6. Predictions (right column) and actual results (left column) of an LRP experiment designed to test whether stimulus onset automatically activated the compatible response (Valle-Inclán \& Redondo, 1998). The upper row contains results and predictions for immediate-reaction trials. The lower row contains those for delayed-reaction trials.

The evidence just summarized is incongruent with explanations for the Simon effect constructed around an automatic activation of the compatible response. ValleInclán and Redondo (1998) tested to see whether the presentation of a stimulus actually activated the compatible response using the LRP. Red or green circles were randomly presented above and below a central fixation point and response keys were located "above" and "below." The assignment of response keys to colors was randomly changed on every trial and presented to the subjects before (immediate-reaction trials) or after (delayed-reaction trials) the presentation of the imperative stimulus (the colored 
circle). In this way, there were four types of trials defined by spatial compatibility and by the moment at which the response keys were defined. The critical manipulation is in the delayed-reaction trials. If one assumes that the stimulus presentation activates the spatially compatible response, the LRP should show signs of response activation in the interval between the stimulus presentation and the definition of the response keys. The predicted pattern of results according to this hypothesis is shown in Figure 6. right panel. The results, illustrated in the left pancl of Figure 6 , confirm that the presentation of a stimulus does not activate the spatially compatihic response.

Recently, we have begun to study the role of expectations in the Simon effect, measuring the influence of sequential dependencies. The influence of a trial (N-1) on the following one $(\mathrm{N})$ is pervasive in chroce-RT tasks, and repetition effocts (the $\left.\mathrm{RT}_{n}<\mathrm{RT}_{n-1}\right)$ and allernation effects $\left(\mathrm{RT}_{n}>\mathrm{RT}_{n-1}\right)$ have been described. The repetition effects appear at relatively short intervals between the response and stimulus (RSI, response-to-stimulus interval) and are linked to perceptive processing. The atternation effects, on the contrary, appear at long RSIs and are linked to response factors. This patern varies when stimuli and responses are spatially incompatible. and repetition effects with RSI greatcr than 1000 ms can be observed.

Valle-Inclán ct at. (1998) studied the effects of computibility between trial $\mathrm{N}-1$ and trial $N$ in a Simon task. On each trial, they presented in the center of a screen a letter ( $\mathrm{S}$ or $\mathrm{T}$ ). Simultaneous with the appearance of the letter, they presented a noise of $65 \mathrm{~dB}$ through one of the loudspeakers located above or below the monitor. The noise was not informarive, and its localization, up or down, was random. Responses to the letter were given pressing "upper" or "lower" keys.

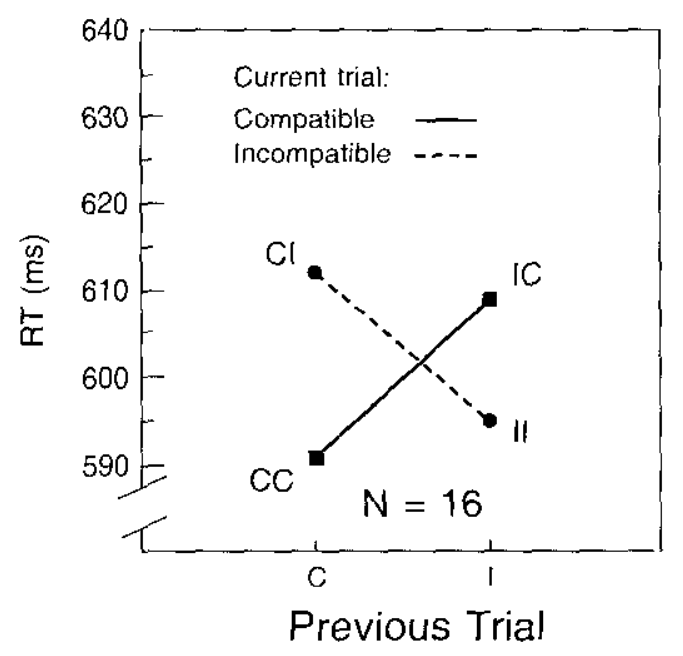

Figure 7 . Sequential dependencies in a Simon task (from ValleInclán, Hackley, \& McClay, 1998).
The RT analyses included only those sequences with correct responses in the two conseculive trials. The trials were classified according to compatibility between the trials $\mathrm{N}$ and $\mathrm{N}-1$, yiclding four types of sequences: compatiblecompatible (CC), compatible-incompatible (CI), incompatiblecompatible (IC), and incompatible-incomputible (II). Figurc 7 displays the mean RTs for each of the four sequences. The Simon effect (compatible < incompatible) is present only if the preceding trial was compatible, and an inversion of the Simon effect (compatible $>$ incompatible) is produced if the preceding trial was incompatible. This inversion of the Simon effect contradicts the supposition of an automatic activation of the compatible response; instead, it suggest. that strategic factors are crucial in the production of the effect. More specifically, it suggests the cxistence of a repetition effect of spatial stimulus-response compatibility (SRC).

To test this SRC-repctition effect, we reemployed the procedure of an experiment that attained Simon eftects at about 50 ms (Valle-Inclín, 1996a, Experinent 3). Sixteen students participated voluntarily. The stimuli were arrows pointing up or down, presented randomly above or below the point of fixation, for a period of $50 \mathrm{~ms}$. Responses were made by pressing the keys of a computer keyboard that was placed perpendicular to the screen. The "upper" key was the number 5 and the "lower" key, number 6 , both of the numerical keyboard. The keys were pressed with the index fingers of each hand, and the assignment of key to hand was counterbalinced among the subjects. "The subjects' task consisted of pressing the "upper" key if the arrow pointed up and the "lower" key if the arrow pointed down.

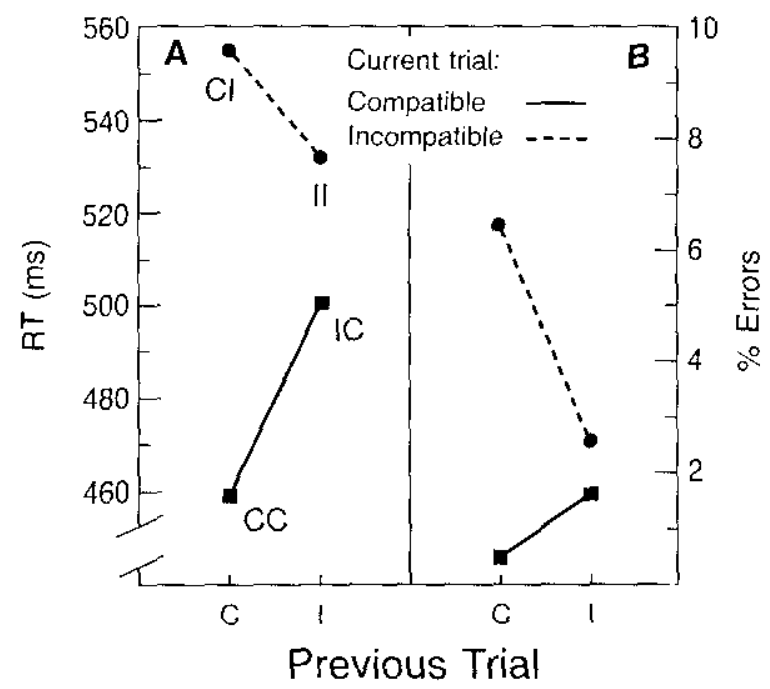

Figure 8. Sequential dependencies in a Simon task after VatteInclán (1996. Experiment 3). The pincl on the left contains the mean RT and the right panel shows the mean percentage of ercors. $\mathrm{C}=$ Compatible; $\mathrm{I}=$ Incompatibie $; \mathrm{CC}=$ Compatible-Compatible: $\mathbf{C l}=$ Compatible-Incompatible; $\mathbf{I C}=$ Incompatible-Compatib]e; $\mathbf{I I}$ = Incompatible-Incompatible. 
The trials were classified according to the compatibility between the preceding trial and the current trial, just as in the experiment of Valle-Inclán et al. (1998). The compatible trials had faster RTs ( $487 \mathrm{msec}$ ) than the incompatible trials $(549 \mathrm{msec}), F(1,15)=109.92, p<.0001$, and a lower percentage of error $(1.17 \%$ and $5.17 \%$, respectively), $F(1$, 15) $=17.95, p<.0001$. The results of the analysis of sequential compatibility are shown in Figure 8. The left panel includes the mean RTs for cach of the four sequences of compatibility $(\mathrm{CC}, \mathrm{Cl}, \mathrm{IC}, \mathrm{II})$, and the right panel contains the averages of percentage of error for each of the conditions (to obtain this measure, only sequences in which the first trial had been answered correctly were included). A strong SRC-repetition effect ( $\mathrm{CC}<\mathrm{IC}$ and $\mathrm{ll}<\mathrm{Cl}$ ) was observed in $\mathrm{RT}$ and percentage of error, although the Simon effect did not become inverted after incompatibie trials, as in ValleInclán et al. (1998). Figure 8 shows that the greatest contribution to the Simon effect was produced by the difference between $\mathrm{CC}(459 \mathrm{msec})$ and $\mathrm{Cl}(555 \mathrm{msec})$ although there was also a contribution in the difference between IC (501 msec) and II (532 msec). Interaction between compatibility in the preceding trial and in the current trial was very strong, $F(1,15)=113.1, p<.0001$, just as the main compatibility effect for the current trial, $F(1,15)=117.51, p<.0001$

These results suggest that subjects expect repetition of S-R compatibility (trials CC and II). If, instead of repetition, alternation is presented (CI or IC), the RTs are longer and precision diminishes. The results also indicate that the SRCrepetition effect is greater when trial $\mathrm{N}-1$ is compatible (difference between $\mathrm{CC}$ and $\mathrm{Cl}, 96 \mathrm{msec}$ ) than when it is incompatible (difference between II and IC, $31 \mathrm{msec}$ ). The causes for this asymmetry are not known, but we believe that it may be a consequence of overestimation of the number of compatible trials. In turn, this overestimation could be caused by daily experience, where spatial compatibility is the norm (Valle-Inclán, Hackley, \& de Labra, 2000).

\section{The Locus of the Accessory Etfect}

The accessory effect is another of the tasks in which irrelevant information affects the processing of relevant information, but, in this case, there is no conflict between Iwo responses. In a choice-RT task with visual targets, if an irrelevant noise (that calls for no response, gives no information about which is the correct response, and provokes no blinking reflex) is presented on some trials, RT is shorter for those trials with noise (accessory stimulus) than for those without (see Nikerson's classic revision, 1973).

Explitnations for this effect have been offered for each of the three stages of information processing of Figure 2. It has been suggested that the accessory effect reflects intersensory facilitation (Stein, London, Wilkinson, \& Price, 1996), an increase in the specd with which the response is selected (Posner, 1978), and an increase in the speed with which the response is prepared and execuled (Sanders, 1980). In view of these conflicting explanations, it is difficult to see how behavioral data alone could localize the processing stage. However, use of the LRP makes it perfectly possible to divide the RT in two and note whether the accessory effect is produced in one half or the other.

Hackley and Valle-Inclín (1998, 1999) applicd this reasoning and found that the facilitation is produced before response selection ends; that is, the entire behavioral effect is reflected in the stimulus-locked LRP, and there are no traces of facilitation in the response-locked LRP. One can conclude that the accessory effect occurs either during the perceptive processing or during response selection. The next step is to demonstrate in which one of the two the behavioral effect originates. This is no easy task. The fundamental problem lics in the confusion of visual and auditory ERPs on trials with an accessory stimulus. Separating the two contributions requires some sophistication in the experimental design and in the treatment of data, but this does not appear to be impossible to achieve.

Another interesting outcome from the work of Hackley and Valle-Inclán (1999) is the utilization of blinking latency. It is known that subjects tend to blink on finishing a trial (Stem, Walrath, \& Goldstein, 1984), and this holds for trials that require in response ("go trials") and for those that do not require a response ("no-go trials"). This means that, even in the trials for which the subject does not have to press a key, the recording of blinks allows one to know when the subject has finished processing the stimulus and has decided not to respond (see Figure 3 of Hackley \& Valle-Inclán, 1999). We would like to call attention to this finding, which provides for measuring ' $\mathrm{RT}$ ' in trials where there is no response.

\section{Concluding Remarks}

The research summarized in this paper provides an example of the way in which physiological measures can be used to test information-processing models of human brain functioning. We have focused on one physiological measure, the LRP, that yields an index of differential activation between left and right motor cortex. Unlike other ERPs, the neural generators of the LRP are relatively well known, and its functional significance is clear, or, at least, is understood more clearly than any other ERP.

Using the LRP, we showed that: (a) The Simon effect is due, at least in part, to response interference produced by activation of the compatible response on incompatible trials (Valle-Inclán, 1996a, 1996b); (b) the activation of the compatible response should not be considered an automatic, stimulus-driven process (Valle-Inclán \& Redondo, 1998); and (c) the observed behavioral facilitation in the accessory effect is produced before the response selection ends (Hackley \& Valle-Inclán, 1998, 1999). 


\section{References}

Coles, M.G.H. (1989). Modern mind-brain readjng: Psychophysiology, physiology, and cognition. Psychophysiology, 26, 251-269.

Coles, M.G.H., \& Gratton, G. (1986). Cognitive psychophysiology and the study of states and processes. In G.R.J. I lockey. A.W.K. Gaillard, \& M.G.H. Coles (Eds.), Energetics and human information processing (pp. 409-424). Dordrecht, The Netheriands: Martinus Nijhoff.

Craft, J.L., \& Sinon, J.R. (1970). Processing symbolic information from a visual display: Interference from an irrelevant directional cue. Jounal of Experimental Pswchology, 83, 415-420.

de Jong, R., liang, C., \& Liuber, E. (1994), Conditional and unconditional antomaticity: A dual-process model of etfects of spatial stimulus-response correspondence. Jounial of Experintental Psychology: Human Perception and Performance, 20, 731-750.

de Jong, R.. Wierda, M., Mulder, G., \& Mulder, L.J.M. (1988). Use of partial information in response processing. Joumal of Experinental Psychology: Haman Perception and Perfomance. 14, 682-692.

Eriksen, B.A.. \& Eriksen, C.W. (1974). Effects of noise letters upon the identification of a target letter in a nonsearch task. Perception and Psychophysics, 10, 143-149.

Gratton, G., Coles, M.G.H.. \& Donchin, F. (1983). A new method for off-line removal of ocular artifacts. Electromephalograhy and Clinical Neurophysiology, 55, 468-484.

Gratton, G.. Coles, M.G.H., \& Donchin. E. (1992). Optimizing the use of information: Strategic control of activation of responses. Joumal of Experimental Prychology: General, 121, 4480-4506.

Grice. G.R., Canham, L., \& Boroughs, J.M. (1984). Combination rule for redundant information in reaction time tasks with divided attention. Perception \& Psychophysics, 36, 451-463.

Hackley, S.A.. \& Valle-Inclán, I: (1998). Automatic alerting does not speed late motoric processes in a reaction time task. Nature, $39 /, 786-788$.

Hackley, S.A., \& Valle-Inclán, F. (1999). Accessory stimulus effects on response selection: Does arousal speed decision making? Journal of Cognitive Newrosience, 11, 321-329.

Hasbroucq. T., \& Guiard, Y. (1991). Stimulus-response compatibility and the Simon effect: Toward a conceptual clarification. Joumal of Experimenal Prychology: Haman Perception and Performante, 17, 246-266.

Hedge. A., \& Marsh. N.W.A. (1975). The effects of irrelevant spatial correspondences on two-choice tesponse-time. Acta Psychologica, 39, 427-439.

Hillyard, S.A., Hink. R.F., Schwent, V.L.., \& Picton, T.W. (1973). Electrical signals of selective attention in the human brain. Science, 182, 177-180.

Hommel, B. (1993a). The relationship between stimulus processing and response selection in the Simon task: Evidence for a temporal overlap. Psychological Rescarch/Psychologische Forschung, 55, 280-290.

Hommel, B. (1993b). Inverting the Simou etfect by intention: Determinants of direction and extent of effects of irrelevant spatial information. Psychological Research/Psychologische Forschung, 55, 270-279.

Hommel, B. (1994). Spontaneous decay of response-code activation. Prychological Researdh/Prychologische Forschtng, 56, 261268.

Hommcl. B. (1995). Stimulus-response compatibility and the Simon effect: Toward an empirical clarification. Joumal of Experinemal Psychology: Human Perception and Perfontante, $21,764-775$.

Kornblum, S., Iashroucq. T.. \& Osman, A. (1990). Dimensional overlap: Cognilive basis for stimulus-response compalibility: A model and taxonomy. Psychological Review 97. 253-270.

Kornblum, S., Stcvens. G.T., Requin, J., \& Whipple, A. (1999). The effects of irrelevalut stimuli: 1 . The time course of stimulusstimulus and stimulus-response consistency effects with Strooplike stimuli, Simon-like tasks, and their factorial combinations. Joumal of Experimental Psychology. Hamom Perception and Performance, 25, 688-714.

Lu, C.-H., \& Proctor, R.W. (1995). The intluence of irrelevant location inlormation on performance: A review of the Simon and spatial Stroop effects. Psychonomic Bulletin \& Review; 2. 174-207.

McCartly, G., \& Donchis, E. (1981). A metric for thought: A comparison of $\mathrm{P} 300$ latency and reaction time. Science, 21 . $77-80$.

Nickerson. R.S. (1973). Intersensory facilitation of reaction time: Encrgy sumnation or preparation enhancement? Psychological Reven; 80. 489-509.

Osman, A.. Bashore, T.R., Coles, M.G.H., Donchin, E., \& Meyer, D.E. (1992). On the transmission of partial information: Inferences from movement-related brain potentials. Journal of Experimental Psychology: Homan Perception and Performance, 18. 217-232.

Posner, M.1. (1978). Chronometric explorations of the mind. Hillsdalc. NJ: Lrlbaum.

Proctor. R.W. \& I.u, C.-H. (1999). Processing irrelevant location information: Practice and transfer effects in choice-reaction tasks. Menory \& Cognition, 27, 63-77.

Sanders, A.t. (1980). Stage analysis of reaction processes. In Gi.E. Stelmach \& J. Requin (Eds). Trtorials in motor behavior (pp. 331-354). Amsterdam: North l lolland.

Shiu. L..P., \& Kornblum, S. (1999). Stimulus-response compatibility effects in go-no-go lasks: A dimensional overlap account. Ferception \& Psychoplysics, 6/, 1613-1623.

Simon, J.R. (1990). The effects of an irrelevant directional cue on human information processing. In R.W. Proctor \& T.G. Reeve (Eds.), Stimulus-Response compatibility: An integrated perspective (pp. 31-88). Ansterdam: North-Holland.

Simon, J.R., \& Acosta, E.. Jr. (1982). Effect of itrelevant information on the processing of relevant information: Facilitation and/or interference? The influence of experimental desigu. Perception \& Pychophysics, 31. 383-388.

Simon, J.R., \& Craft. J.L. (1970). Effects of an irrelevant aluditory stimulus on visual choice renction time. Journal of Experimental Psycholog, 86, 272-274 
Simon, J.R., Hinrichs, J.V., \& Craft, J.L. (1970). Auditory S-R compatibility: Reaction time as a function of ear-hand correspondence and ear-response-location correspondence. Jounal of Experimental Psychology 86, 97-102.

Simon, J.R., \& Rudell, A.P. (1967). Auditory S-R compatibility: The effect of an irrelevant cue on information processing. Journal of Applied Psychology, 51, 300-304.

Simon, J.R., \& Small, A.M., Jr. (1969). Processing auditory information: Interference from an irrelevant cue. Journal of Applied Psychology, 53, 433-435.

Smid, H.G.O.M., Mulder, G., \& Mulder, L.J.M. (1987). The continuous flow model revisited: Perceptual and motor aspects. In R.E. Johnson, J.W. Rohrbaugh, \& R. Parasuraman (Eds.), Current trends in event-related potentials research. Electroencephalography and Clinical Neurophysiology (Suppl. 40) (pp. 270-278). Amsterdam: Elsevier.

Stein, B.E., London, N., Wilkinson, L.K., \& Price, D.D. (1996). Enhancement of perceived visual intensity by auditory stimuli: A psychophysical analysis. Joumal of Cognitive Neuroscience, $8,497-506$

Stern, J.A., Walrath, L.C., \& Goldstein, R. (1984). The endogenous eyeblink. Psychophysiology, 21, 22-33.

Stroop, J.R. (1935). Studies of interference in serial verbal reactions. Joumal of Experimental Psychology, 18, 643-662.

Umilà, C., Rubichi, S., \& Nicoletti, R. (1999). Facilitation and interference components in the Simon effect. Archives Italiennes de Biologie, 137, 139-149.
Valle-Inclán, F. (1996a). The locus of interference in the Simon effect: An ERP study. Biological Psychology, 43, 147-162.

Valle-Inclán, F. (1996b). The Simon effect and its reversal studied with ERPs. International Joumal of Psychophysiology, 23, 4153.

Valle-Inclán, F., Hackley, S.A., \& de Labra, C. (2000). Expectancies and spatial coding in the Simon effect. Manuscript in preparation.

Valle-Inclán, F., Hackley, S.A., de Labra, C., \& Alvarez, A. (1999a). Early visual processing during binocular rivalry studied with visual evoked potentials. NetroReport, 10, 21-25.

Valle-Inclán, F., Hackley, S.A., de Labra, C., \& Alvarez, A. (1999b). Rivalry related potential does not originate in striate cortex. Psychophysiology. 36, supp. 1, S117.

Valle-Inclán, F., Hackley, S.A., \& McClay, B. (1998). Sequential effects with respect to the Simon effect. Journal of Psychophysiology, 12, 404.

Valle-Inclán, F, \& Redondo, M. (1998). On the automaticity of ipsilateral response activation in the Simon effect. Psychophysiology, 35, 366-371.

Verleger, R. (1997). On the utility of P3 latency as an index of mental chronometry. Psychophysiology, 34, 131-156.

Received February 16, 2000 Revision received February 28, 2000 Accepted March 15, 2000 